\title{
Research on the Structure of Human Capital and the Choice of Technical \\ Level and the Motive Force of Economic Growth in Xi'an
}

\author{
Huiai Yuan ${ }^{1}$, Lihong Zhao ${ }^{1}$, Chenhan Yuan ${ }^{2}$ \\ ${ }^{1}$ Shanxi Institute of International Trade, Commerce, Xi'an, Shanxi, 712046 \\ ${ }^{2}$ Chengdu University of Technology, Chendu, Sichuan, 610059
}

Keywords: Human Capital, Technical Level Choice, Economic Growth

\begin{abstract}
In general, human capital is concentrated in the city, especially in the city where educational science and technology resources are more enriched. Therefore, the enrichment of science and technology resources is the most ideal place for human capital research. As the economic and financial center of the northwest region, Xi'an has gathered a large number of scientific research (higher education institutions and high-tech industries, science and technology resources enrichment), in addition to the important strategic position. The contribution of human capital to economic growth in this city can not be neglected. This paper takes Xi'an as an example to focus on the contribution of human capital in the process of economic growth.
\end{abstract}

\section{Introduction}

Since the reform and opening up, China's urban economic development has made remarkable achievements. But at the same time, the east and west urban economic development imbalance is also manifested. Moreover, in the course of urban economic development, the asymmetry of urban resource advantage and economic development advantage is particularly worthy of attention. For example, the human capital index between cities does not match the performance of economic growth over the same period. Many cities do not have human capital advantage, But it has achieved rapid economic growth; on the contrary, some cities with human capital advantages, economic growth performance is not ideal.

The impact of urban economy on the economic and social development of a country is a multifaceted, serious and expanding urban economic growth level. It is not only detrimental to the rational allocation of resources and the sustained, rapid and healthy development of the national economy, but also the stability of society National political and economic unity. Therefore, the causes, mechanisms and countermeasures of the difference of urban economic growth are the important contents of the study of urban economic development. For the interpretation of differences in urban economic growth, academia has always had a different view. First, the institutional determinism, the difference between urban economic growth is attributed to the implementation of the country's non-balanced development strategy; Second, the external determinism, the urban economic growth is the difference between the degree of the city's opening up, and the decision of foreign investment The third is the cultural determinism, the difference between urban economic growth comes down to the traditional concept of local people, such as market economy awareness, entrepreneurship and innovation awareness; Fourth, the location factor determinism, the urban economic growth is the difference attributed to the city The location of the natural resources, and so on. But the policy tilt can not fully explain the economic development of 
the southeast coast of China is better than the central and western inland economic development. Moreover, the location factors, external factors only constitute the necessary conditions for the development of urban economy. And cultural phenomena for the interpretation of urban economic development differences do not have a general. Therefore, we must look for other factors that affect the economic development of the city.

Human capital accumulation affect the role of urban economic growth mechanism of the economy belongs to the typical human capital pull type, the future growth of the economy in Xi'an will rely mainly on the improvement of labor quality, not just the increase in the number of practitioners, the results also show that, The contribution of human capital to economic growth in Xi'an shows a strong cyclical fluctuation. At the same time, the absorptive capacity of human capital is weak and the technological progress is slow. In order to fully exploit the advantages of human capital and realize the key resources of human capital and other factors of production efficient combination, this paper put forward the following suggestions:

To improve the education system, Xi'an must overcome the criticism of the education system and industry out of line, promote scientific and technological innovation and system reform. Encourage investment in private education, get rid of education on the government's excessive financial expenditure, give full play to the market distribution of educational resources, And the combination of market allocation, integration of innovative resources, the construction of distinctive characteristics and outstanding advantages of regional innovation system, relying on high-tech development zones and high-tech industrial base, improve urban competitiveness.

The establishment of a sound incentive mechanism and the introduction of talent mechanism, human capital has (private goods) and (public goods) of the dual nature of which (public goods) determines the characteristics of human capital in the use of the process has a strong competitive at the same time Can only be used by a department or region, through effective incentives, can obtain the effective use of human capital to avoid the loss of human capital\% At the same time, (personal items) determines the characteristics of human capital and talent itself inseparable and the use of the process In the exclusivity, we must through effective incentives to stimulate the innovative ability of practitioners, from the scientific environment, employment mechanism and pay standards to improve the existing incentive mechanism to maximize the human capital to play,

Through the institutional innovation, it improves the efficiency of human capital allocation, human capital after the formation of a reasonable allocation and effective use in order to long-term promotion of sustained economic growth. Xi'an to increase the attractiveness of high-level talent at the same time should also improve the software and hardware service facilities, For the full play of human capital to provide a strong guarantee at the same time, should speed up industrial restructuring, human capital, physical capital and technological progress comprehensive advantages, so that human capital and the corresponding industry to match.

\section{Relationship between Technology Choice and Economic Growth}

Technological progress has become the dominant factor in economic growth and has become the main source of economic efficiency improvement. This chapter mainly discusses the theoretical relationship between technology choice and economic growth by using Marxist economics and western economics' theoretical point of view on technological choice and economic growth, drawing lessons from it, applying and absorbing its beneficial results.

Economic growth can be achieved by an increase in labor input, an increase in capital investment, and an increase in the efficiency of these inputs. The former is the extension of the expansion of reproduction, which is the expansion of the connotation of reproduction. In order to achieve 
sustained economic growth, it is important to invest in elements. However, in the development of human society, the problems of population, food, energy, resources and environment caused by various factors have made it possible to support the sustained growth of the economy by increasing the output efficiency of the input factors. Relying on scientific and technological progress, improve the technology selection policy is to improve the efficiency of production factors, is the main way to achieve sustained economic growth.

The exponential effect of science and technology, mainly from the science and technology for the production and economic development of the great role in promoting, that is, science and technology has become the first decisive factor in the development of modern economy. Marx has long talked about the labor of science and technology as a simple labor is self-employed or multiplied, that is the same amount of labor time, science and technology can create much more than the value of simple labor. And modern science and technology as the most advanced productive forces, on other factors of production more magical magnification effect.

The infiltration effect of science and technology is mainly to explain the status and function of science and technology from the perspective of science and technology to the social function of science and technology in all areas of society, and the influence of science and technology on the cornerstone of building modern civilization. Mainly in the following aspects: the development of science and technology has greatly opened up the field of human and natural relations, so that human beings into the free kingdom, the owner of nature and no longer a slave to nature, so that human beings can more effectively use resources, Control the population, improve and protect the environment. Science and technology also has a strong ideological change function, it inspires people's scientific thinking, cultivate people's scientific spirit, scientific attitude, scientific methods and scientific management. And to explore the scientific spirit of innovation, the scientific attitude of seeking truth from facts, materialist dialectical scientific methods, strict and orderly scientific management complement each other, with the transformation of human beings, the objective world of the powerful function of building a modern civilization is a powerful weapon.

\section{Technology Choice and Realization of the Strategy of Rapid Economic Growth}

Due to the complexity and uncertainty of technological innovation, it is difficult for enterprises to independently support the excessive cost and risk in the application of key technology research. This determines that in the process of key technology implementation, the government should strengthen macro policy guidance and increase the key technology Project research investment. In addition to increasing the financial input of the key technologies of public welfare, the government should encourage and support the enterprises to increase the research of key technologies and promote the investment in the application according to the market situation, and gradually establish the incentive mechanism of science and technology to adapt to the laws of the market economy. Through the regular development of industrial technology policy, the government encourages all kinds of venture capital to enter the key key technology fields, strengthen the key high-tech research, introduce and digest the absorption, promote the wide application of key technologies.

Significant technology introduction projects, must be introduced after the digestion and absorption program. In the mastery and application of the introduction of technology on the basis of the combination of domestic scientific research to repay the software technology and hardware technology for domestic production and improve the management of the transformation and innovation in supporting technology, equipment, raw materials, components and components to improve domestic To the level of self-made, as far as possible the digestion and absorption of the results of transplantation, grafting research, the domestic application of a wide range of needs of a 
large number of projects in the introduction of advanced technology on the basis of digestion, absorption, The two combine with each other to shorten the research and development cycle, improve the efficiency of research and development work, faster reach the world advanced level. At present, the proportion of technology development and development (that is, the development work for the purpose of digestion and absorption of technology) is about $10 \%$, and should be increased to more than $30 \%$.

Around the introduction of major technology projects need to have the flow of technology to absorb the scientific research team. Technology and equipment conditions and weak technical force of the introduction of units, should be organized by the joint production and research and scientific research team, commitment to the introduction of technology flow of work to absorb the work. Various technology development enterprise group company's technology center to pilot base, workshop and other major research and test conditions, assume the country and industry, the region's major technology to introduce the digestion and absorption tasks. Digestion and innovation of the results and income, by the introduction of units and digestive units to share and form a contract to clarify the rights and obligations of both parties, the use of the introduction of paid technology and valuable transfer of digestion, innovative technological achievements.

\section{Conclusion}

Urban economic growth is an important research topic in economics. Many scholars at home and abroad try to explain the economic growth and the difference of modern city from the perspectives of regional advantages, policy differences, external factors, cultural background and material capital investment. However, in the context of the city's progress towards the knowledge economy and the increasing role of human capital in economic growth, these theories can not provide satisfactory solutions to the modern urban economic growth and its differences. Based on the theory of human capital, based on the existing human capital, economic growth and urban economic growth theory, this paper constructs the framework of urban economic growth analysis based on human capital. Based on this, this paper tries to make up for the omissions and shortcomings of traditional urban economic growth theory. And try to analyze its mechanism of action, so as to make a more reasonable explanation of the economic growth of the modern city and its differences.

\section{Acknowledgements}

Xi'an Planning Project of Social science (16J72): The Interactive Research of Human Capital Structure, Choice of Technological Level and $\mathrm{Xi}^{\prime}$ an Economic Growth.

\section{References}

[1] Zhang Mingxing, Sun Yue, Zhu Min. The imitation of the introduction, independent innovation technology strategy model selection [J]. Finance and Economics, 2006 (08)

[2] Gao Yingbin, Luo Shixian. Under the scientific development concept as a guide to promote scientific and technological innovation [J]. Shopping modernization, 2006 (20)

[3] Xiao Nan. "Eleventh Five-Year Plan" in the economic growth theory [J]. Decision and Information, 2006 (06)

[4] Hou Lunguang. Independent innovation is a major measure to implement the scientific concept of development [J]. Mao Zedong Thought Research, 2006 (02)

[5] Du Danli. DEA selection of advanced manufacturing technology [J]. Industrial Technology and Economy, 2006 (02) 
[6] Li Jianmin. Technology diffusion, technology monopoly and China's technological strategy change [J]. China Science and Technology Forum, 2006 (02) 